paper on which to print his logarithmic tables. The early volumes contain Soelberg Wells's papers on paralytic affections of the muscles of the eye, and Jonathan Hutchinson's on syphilitic inflammations of the eye. Here, too, are Hughlings Jackson's papers on defects of sight in diseases of the nervous system. In vols. iii and iv he finds chiefly optic atrophy; in vol. iv he distinguishes between nerve atrophy (primary) and cerebral atrophy (post-neuritic); in vol. viii he publishes two cases, one of cerebral tumour without optic neuritis, and another of double optic neuritis without cerebral tumour.

And so we may bid farewell. The familiar brown-covered parts will no longer be seen. The spirit which gave them birth sometimes flagged, but never died. It is not dead now, but re-kindled into a newer and livelier flame. Le roi est mort! Vive le roi!"

\title{
The War Activities of an Ophthalmological Society
}

An interesting account of the work accomplished by the Ophthalmological Society of Paris during the war is given by Rochon Duvigneaud in the Annales d'Oculistique of July last.

The Society has been by no means idle in the period under review. In October, 1914, it addressed a letter to the authorities asking for a better distribution of wounded soldiers in the special hospitals of Paris, and furnished the necessary information dealing with this subject. A second letter was sent to the Minister of War, advocating the advantages of introducing cylindrical lenses into the optical correction allowed to soldiers : shortly afterwards a ministerial decision was promulgated to the effect that astigmatism was compatible with service in the field when the visual defect was adequately compensated by cylindrical glasses. In 1916 the Society recommenced its regular meetings, compensating the absence of such of its members as had been mobilized by the admission to its meetings of ophthalmologists, native and allied, who were stationed in Paris, as Bourgeois, Moreau, Genet, Roy (Canadian Army), Quentin, Coulomb, etc.

In April and July, 1916, and in May, 1917, the Society devoted three meetings to the discussion of war subjects. The importance of these meetings was recognized by the authorities, as shown by the fact that they were presided over by M. Justin Godart, the Under Secretary of State of the Military Sanitary Service, who was accompanied by his medical staff. The Society is at present organizing another of these meetings, to be held during the ensuing winter. The participation of all mobilized ophthalmologists is invited. The titles of communications must be submitted, through the Society, to the Under Secretary of State, who will be asked to preside over the meeting. 
Meanwhile the ordinary meetings of the Society were largely taken up with military subjects. The special war meetings included the discussion of the organization of the military ophthalmological services the correction of errors of refraction, and the prevention of war injuries of the eye ; in a word, anything that had a bearing upon prevention. They also included medical and surgical pathology, medico-legal questions, and the problems surrounding those blinded in the war. Briefly, the Society undertook everything in its power to repair the damage caused by war, therapeutically, morally, or pecuniarily. In March, 1916, the Society transmitted to the Minister of War a report advising certain changes in the military regulations concerning the visual requirements of soldiers, pointing out the number of men whose sight could be brought to the required standard by the employment of sphero-cylindrical glasses. The Society next demanded that all ophthalmic surgeons mobilized should be employed in the pursuit of their speciality, and not be distracted by duties incidental to the exercise of general medicine and surgery. The Society took up the question of the lenses and mountings needed for a given number of men, and suggested that the sight and refraction should be entered upon the soldier's record. . It also gave all the information necessary for the efficient working of centres where glasses might be obtained by ametropic soldiers. The Society has also done good work in protecting the eyes of the soldiers against injuries inflicted by small particles of low penetrative power. Various protective appliances have been devised by its members, as Terrien and Cousin, Monthus, Morax and Moreau, Polack, and Dunant. The problem, however, has yet to be solved. Among other important subjects studied and discussed by the Society may be mentioned the repair of wounds of the face and of the eye, the early treatment of wounds of the eye and eyelids, the management of cicatrized wounds of the eyelids and the orbital cavity, questions surrounding the wearing of an artificial eye, intra-ocular foreign bodies, the relationship between wounds of the cranium and disorders of sight, injuries by "windage," nightblindness, and factitious disease, as well as simulated defect of sight, to say nothing of such medico-legal questions as the estimation of the degree of invalidity caused by hemianopsia.

Altogether, the record of the Paris Ophthalmological Society is one to be emulated by similar bodies.

\section{The Welfare of the Blind}

The Departmental Committee on the Welfare of the Blind, appointed early in 1914 by the then President of the Local Government Board, has issued its Report. It is of interest to note that the Chairman of the Committee, the Right Hon. W. Hayes Fisher, M.P., 